Western University Scholarship@Western

Centre for the Study of International Economic Centre for the Study of International Economic

Relations Working Papers

Relations

1982

\title{
Friedman and Schwartz on Monetary Trends - A Review Article
}

David Laidler

Follow this and additional works at: https://ir.lib.uwo.ca/economicscsier_wp

Part of the Economics Commons

Citation of this paper:

Laidler, David. "Friedman and Schwartz on Monetary Trends - A Review Article." Centre for the Study of International Economic Relations Working Papers, 8211C. London, ON: Department of Economics, University of Western Ontario (1982). 
CENTRE FOR THE STUDY OF INTERNATIONAL ECONOMIC RELATIONS

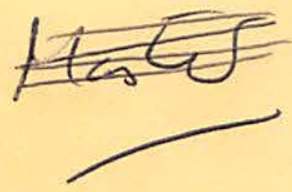

WORKING PAPER NO. $8211 \mathrm{C}$

FRIEDMAN AND SCHWARTZ ON MONETARY TRENDS - A REVIEW ARTICLE

David Laidler

This paper contains preliminary findings from research work still in progress and should not be quoted without prior approval of the author.

DEPARTMENT OF ECONOMICS UNIVERSITY OF WESTERN ONTARIO LONDON, CANADA N6A $5 \mathrm{C} 2$ 
Friedman and Schwartz on Monetary Trends - A Review Article*

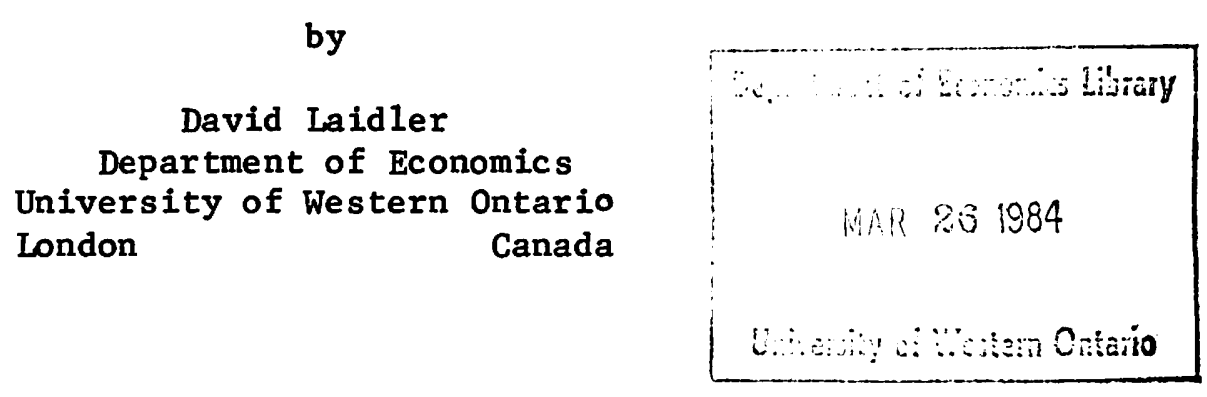

I

Monetary Trends is a marvellous book. It is not always easy reading, but it is original, thoughtful, stimulating, and above all careful. I can think of no work in applied econometrics whose authors have given as much attention as have Friedman and Schwartz to making clear to the reader where the data employed come from, how they have been adjusted, and how the adjustments in question may or may not affect the results generated. Nor can I think of any single quantitative work that has addressed so central and comprehensive a question as does this one, for Monetary Trends is nothing less than an attempt to settle the debate between "Keynesian Economics" and the "Quantity Theory of Money" in the light of the evidence generated by Great Britain and the United States over the period 1867-1975.

Though the book can certainly be read in isolation, the reader who is already familiar with Friedman and Schwartz's two earlier works, The Monetary History... and Monetary Statistics of the United States (1963a, 1970) and Philip Cagan's Determinants and Effects of Changes in the Stock of Money (1965) is undoubtedly at something of an advantage, if only because he will know that certain issues which appear to be taken for 
granted in this book have been squarely addressed elsewhere: is it really wise to treat fluctuations in the money supply as exogenous to those in real income and output? see Cagan, and Friedman and Schwartz (1963); is $M_{2}$ really the most appropriate measure of the money supply when the quantity theory is tested? see Friedman and Schwartz (1970); and so on. The close relationship between Monetary Trends and its predecessor volumes is one of its great strengths, but it is also a source of one of its few weaknesses. Those earlier books dealt only with the United States, and this one deals with the United Kingdom as well. Not all the United Kingdom results presented here rest on such firm foundations as do those for the United States.

As I have already hinted, rather than being economic history this is a work of applied econometrics. The focus is on testing economic hypotheses using time series data, rather than on explaining the whys and wherefores of particular episodes. Nevertheless the reader who looks for the deployment of so-called "best professional practice" estimation techniques in Monetary Trends will be disappointed. The econometrics per se never relies on anything more complex than least squares estimators, sometimes constrained to observe non-linear relationships among the parameters, and frequently generated from running the regression both ways in order to deal with measurement errors. Much of the analysis is carried on with the aid of tables and charts. The ratio of human intelligence to computer time that has gone into the production of this book is, that is to say, refreshingly high. However, even a reader such as myse1f, who is somewhat suspicious about contemporary trends in econometrics, which seem to stress the application of ever more sophisticated estimators to the same old crude and ill understood data, is disappointed that Friedman 
and Schwartz did not tell us something about the time series properties of their residuals. Even simple Durbin-Watson statistics would have made many of their results more informative.

As the reader will have gathered by now, I find it difficult seriously to fault this book. Nevertheless, the foregoing comments are not just quibbles. They do provide reasons for suspecting that some, at least, of Friedman and Schwartz's conclusions are more tentative than others, and occasionally less robust than the careless reader, who concentrates on the passages of this volume which summarize the results, might end up believing. This does not mean that I think any of Friedman and Schwartz's conclusions obviously to be wrong, or any of their tests clearly to be misconceived. It simply means that, even after the prodigious effort that has gone into this book, not to mention its predecessors, certain important questions remain to be explored in more depth. Once I have given the reader a brief account of the contents of the book and of its empirical and theoretical bases, I shall return to these questions in more detail.

II

Monetary Trends consists of twelve chapters, as we11 as a Preface and an introductory summary of its Principal Empirical Findings. After a brief first chapter that sets the scene, Chapter 2 gives a lengthy account of the theoretical issues on which evidence is to be brought to bear, an account which sets out the principal characteristics of the "Quantity Theory" and the "Keynesian" alternative. This chapter is in large measure drawn from Friedman's Monetary Framework of 1974. (Gordon, 1974.) Three chapters then describe the statistical framework of the book, the nature of the data 
to be used, and the basic behaviour of money, income, prices, and so on in the two countries over the period of analysis. Only after this lengthy discussion of the data do Friedman and Schwartz bring them to bear on the substantive hypotheses set out in the second chapter. They deal in turn with Velocity and the Demand for Money, the extent to which the United States and the United Kingdom form parts of a single unified financial system, the influence of money on nominal income, the division of nominal income fluctuations between real income and prices (with special attention to the Phillips curve), the influence of money on interest rates (with special attention to the Gibson paradox), and the role of money in generating "long swings" in economic growth. The final chapter summarises the empirical results achieved, and relates them to the theoretical issues raised in Chapter 2 .

Many readers of Monetary Trends will be tempted to go straight from Chapter 2 to Chapter 6, taking the data for granted, but they should not do so, at least on their first reading of the book. The National Bureau tradition, in which this book is so deeply grounded, does not treat data as sources of objective statistical information independent of the hypotheses on which they are to be brought to bear. The way in which data are collected and arranged depends critically upon: the purpose for which they are to be used. Readers of this book who do not understand this, and who do not familiarise themselves with at least the broad characteristics of Friedman and Schwartz's data base,will be in grave danger of misinterpreting their substantive results.

To begin with, and crucially, the book is about Monetary Trends. The word "cycles" disappeared from its title during its two decade gestation period, and it has nothing directly to say about the role of money in generating 
the business cycle.' This simple fact is reflected in the basic unit of observation for virtually all empirical work being the cycle phase average. A cyclical upswing or downswing generates one observation on the level of a variable. Rates of change observations are generated by fitting $\log$. linear time trends to successive triplets of cycle phase averages of these levels. In principle, these procedures should purge the data of cyclical influences, and they probably in fact do so, except for the United States in the 1930s, where the cycle was so violent relative to the secular movement of variables that its influence may well be still present in their cycle phase average behaviour. I shall return to this point later.

Second, and less important, the raw data were occasionally altered even before cycle phase averages of their values were constructed. The most important example of this is the adjustment of the United States money supply data before 1903 to take account of the growing financial sophistication of the economy, an adjustment which lowers the measured rate of growth of the money supply by enough to get rid of almost all the secular fall in the velocity of circulation which characterised that period. There are other examples too, largely having to do with ridding the data on real income and prices of the distorting effects of wartime and peacetime price controls. The econometric purist will no doubt be shocked by all this, but I can see many advantages in purging data of information that is known to be misleading or irrelevant to the issues under study before formal empirical work is undertaken, not least that it helps keep such work technically rather simple. Nevertheless extensive adjustment of the data does influence the outcome of the tests in which they are used. The three chapters dealing with the data go into all of this, and are therefore an integral part of Friedman and Schwartz's exposition, not an unimportant 
digression which all but the hyper-fastidious reader can safely ignore.

I have already noted that the basic aim of Monetary Trends is nothing less than to discriminate between "Keynesian Economics" and the "Quantity Theory". I put quotation marks around both phrases, because the substantive content which Friedman and Schwartz give to them will not meet with universal approval. For them, the sinequa non of the "Quantity Theory" is an empirically stable aggregate demand for real balances function based on a few arguments. The Quantity Theorist's essential vision of macroeconomic fluctuations is presented as one in which money income adjusts to equilibrate the supply and demand for nominal balances in the wake of shocks which predominantly arise on the supply side of the market, and in which, the longer is one's time perspective, the more heavily are money income adjustments concentrated on the price level, and the less on real income. In contrast, for the Keynesian, liquidity preference is said to be unstable, frequently absolute, and always highly interest elastic, while the major sources of macroeconomic disturbances are said to lie on the real side of the economy and particularly in the inducement to invest. For him the price level is either an institutional datum (though not necessarily a constant) or, although endogenously determined by a Phillips curve, is of sufficiently minor importance in equilibrating the macroeconomy that he usually neglects what to the Quantity Theorist is the key distinction in macroeconomics, namely that between the real and nominal values of variables.

Friedman and Patinkin have already extensively debated the relationships among what are here called the "Quantity Theory" and "Keynesian economics" and earlier doctrines (e.g., in Gordon 1974) and I have nothing new to add to a discussion that continues with unabated vigour in the footnotes in this 
volume (see e.g., pp. 45-46). Nevertheless, the "Quantity Theory" advanced by Friedman and Schwartz is a coherent view of the world which demands serious attention quite regardless of its intellectual ancestry. However, I suspect that readers of this volume, whose views of what constitutes Keynesian economics have mainly been conditioned by reading, for example, Modigliani (1977) or Lipsey (1981), will be tempted to look upon Friedman and Schwarts's "Keynesian" economics as something of a straw man. It is nothing of the sort.

Alvin Hansen was far from alone in proclaiming the behavioral irrelevance of the concept of velocity in the passage which Friedman and Schwartz quote (p. 207). Identical sentiments were expressed, for example, by Richard Kahn and Nicholas Kaldor in their evidence to the Radcliffe Committee (1959). Furthermore "cost push" was the predominant theory of wage and price inflation in the 1950 s as a glance at Bronfenbrenner and Holtzman's (1965) survey will confirm, and it remained so well into the 1970s particularly in the United Kingdom. Paul Samuelson and Robert Solow (1960) did present the Phillips curve as a permanent tradeoff and as a stable basis for policy, and it was widely regarded as such in the 1960s. The economists whom I am citing here are not members of some unimportant intellectual fringe. They taught at important universities and were the leaders in the development of what they called Keynesian economics. The fact that it is their brand of Keynesian economics which Friedman and Schwartz attack rather than the much more subtle version set out by, say, Lipsey (1981) has more to do with the fact that Monetary Trends has been nearly twenty years in the writing than with the fact that such economics makes an easy mark. ${ }^{2}$ If it now seems to be so, and perhaps a bit obsolete into the bargain, that surely has a great deal to do 
with Friedman and Schwartz's earlier work. Even so, as Friedman and Schwartz document (e.g., p. 33), self-styled Keynesians who would not dream of propounding the liquidity trap doctrine or the view that prices are institutionally given, are careless about distinguishing between real and nominal balances. Someone for whom the adjustment of the demand for the former to the supply of the latter provides the key to understanding macroeconomic fluctuations, would not be. Thus, though the theoretical alternatives tested in this book were more central to macroeconomics ten or even twenty years ago than they are now, the issues that Friedman and Schwartz address are far from dead, even in 1982 .

\section{III}

Friedman and Schwartz express their "Monetary Theory of Nominal Income" in an equation which has nominal income grow as a function of discrepancies between the quantity of money supplied and demanded, and between the growth rates of those quantities. Thus they set their views firmly apart from both a Keynesian approach, in which the rate of interest would be seen as moving quickly to equilibrate the money market, and a New-Classical approach which, insisting as it does that all macroeconomic observations are generated by the workings of continuously clearing markets, cannot accommodate the idea of a discrepancy between the supply and demand for money. This theory is not easily tested with the single equation empirical techniques which Friedman and Schwartz use, because if the supply of money does differ from the demand, the latter variable becomes unobservable. Hence the demand for money function, the lynchpin of the quantity theory, cannot be estimated directly. Indirect methods, involving the estimation of complete models, such as pioneered by Jonson, Wymer and others (see, e.g., 
Jonson, Moses and Wymer 1976) must be used.

Friedman and Schwartz's "solution" to this problem is to assume that their period of observation is sufficiently long that in fact the economy is "on" its demand for money function, so that the supply of money does after all measure the quantity demanded. Thus, throughout their empirical work they impose a very important constraint upon the macroeconomic dynamics which they are investigating. Even so, their results on the demand for money function are among the strongest and most convincing in the whole book. For both the U.K. and the U.S. the same relationship explains more than a century of data, with only a trivial difference in the real income elasticity of demand (a little over one for the U.S. and a little less for the U.K.) to distinguish them. Moreover real income alone explains so much of the variation in real per capita money holdings that the very crudest constant income velocity form of the quantity theory is shown to have considerable empirical content. No fewer than three interest rate variables, a short nominal rate, the nominal return on real assets (as proxied by the rate of growth of nominal income) and an own rate of return on money are nevertheless shown to be statistically significant, while the hypothesis of homogeneity of degree zero of the demand function in population and prices is confirmed: all this with only a little prior adjustment of the data mainly and the use of a couple of dummy variables to cope with anomalies associated

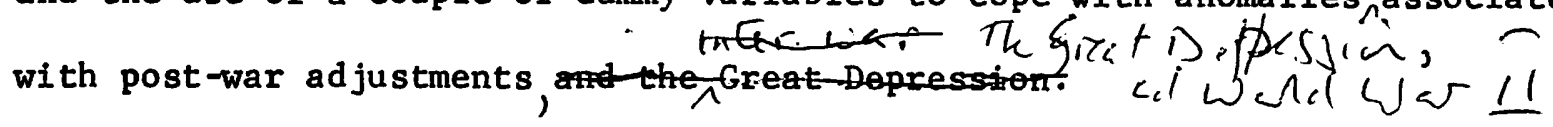
These results are for cycle phase average data and so cast no light on the types of instabilities in the demand for money that have recently been plaguing those who prefer to use quarterly data in their econometrics, but they surely leave no doubt about the validity of this key component of 
Friedman and Schwartz's "quantity theory" explanation of basic monetary relationships. ${ }^{3}$ Nevertheless, a Durbin Watson statistic or two would have been very welcome. Because the appearance of any systematic dynamics in the residuals from Friedman and Schwartz's equations would cast doubt upon the validity of their having assumed that the money market is cleared in cycle phase average data, it would be of considerable interest to know whether or not such patterns are present. This is a question made all the more interesting by the outcome of their work on the dynamics of money income's response to money supply changes. This work shows that particularly in the United States a change in the rate of monetary expansion sets up responses that persist over several cycle phases before a return to steady-state nominal income growth is attained. One cannot help but wonder whether the money market really does equilibrate itself quite as fast as Friedman and Schwartz assume in the light of this evidence on the slowness of the economy as a whole to react to monetary impulses.

\section{IV}

Friedman and Schwartz deal with a model of the determination of money income. Their extreme concern about discrepancies between their estimates of the real income elasticity of demand for real balances for the U.S. and the U.K. probably has its roots in the simple fact that it is only if this elasticity is equal to unity that fluctuations in nominal income can be related precisely to those in the money supply without explicit prior reference to the separate behaviour of real income and prices. As it is, for both countries, the relevant parameter is close enough to unity to render their procedures adequate. Nevertheless, Friedman and Schwartz do not neglect the breakdown of nominal income changes, and one of their more striking claims is to have been unable to find empirical support for the Phillips curve. This conclusion, along with the finding that, for the 
U.K., money has no discernible systematic influence on real income, seems to me to be the easiest in this book to misinterpret.

To begin with Friedman and Schwartz show that, rather than monetary expansion leading both to real income and price level growth, the latter two variables tend to move in opposite directions. Given that the demand function for nominal balances is dominated by real income and the price level, it is hard to see how things could be otherwise, as Friedman and Schwartz themselves point out, but these are not the two variables that the Phillips curve seeks to link, For that relationship, it is the level, rather than the rate of change, of output that one might think relevant, and the former presumably lags the latter by roughly a quarter cycle. Given that the data used here are averages for half a cycle, it is hard to know what to infer about a relationship involving the level of a series from evidence about a relationship that utilises its rate of change. ${ }^{4}$

Of course Friedman and Schwartz produce more direct evidence than this. They do attempt to relate inflation to the level of real income relative int. -vur

to trend among other variables, but only for the United States is the relationship in question at all well determined. There seem to me to be a number of possible reasons for this. First, however suitable it may be over shorter periods, one must question the accuracy of trend real national income as a measure of capacity output over a period as long as 1867-1975. Second Friedman and Schwartz's usual proxy for the expected inflation rate is lagged actual inflation. One really must wonder whether, during a cyclical upswing, the inflation rate over the previous downswing is a good measure of expected inflation, and vice versa. 5

Finally, and probably most important, is it really surprising that, over a period as long as a cycle phase; the effects of monetary expansion have 
already worked through to prices, or that their initial short-run impact on output is largely lost in averaging the data? We already know from Cagan's (1969) study that there is no discernable unemployment inflation tradeoff in cycle phase average U.K. and U.S. data, just as surely as we know from Phillips' original study (1958) that such a trade off is present in certain periods of annual U.K. data.

What we can safely conclude from Friedman and Schwartz's results on the Phillips curve is that it is not a secular phenomenon. That is certainly worth knowing. ${ }^{6}$ However we cannot conclude that it is an unimportant relationship within the cycle. It does after all show up in $\ln l e-v \omega$ U.S. data drand That might be, as Friedman and schwartz argue, because the 1930 sare an anomaly, on whose basis Keynes and his followers overgeneralised, but it might also be because the cycle in the 1930 s was so violent that important traces of its characteristics are still present in Friedman and Schwartz's phase average data for that decade. There is nothing, that is to say, in Friedman and Schwartz's results to contradict the following statement, which many would think a good characterisation of the role of the Phillips curve in dividing up over time the effects of monetary expansion on output and prices.

"Because prices are sticky, faster or slower monetary growth initially affects output and employment. But these effects wear off. After about two years the main effect is on inflation". That is just as well, since the quotation in question is from Friedman's Newsweek column for July 12, 1982. 7

I have already noted that Friedman and Schwartz's results for the U.K. are even more startling at first sight than those for the U.S. Not only is there no Phillips trade-off, but there is no discernable relationship between monetary growth and real income fluctuations. Though 
abstraction from the cycle probably has something to do with these results, I suspect that they reflect deeper issues. ${ }^{8}$. I do not believe that Friedman and Schwartz take enough account of their own evidence about the interdependence of the monetary systems of their two countries when they come to deal with U.K. data, or make sufficient allowance for certain important events in U.K. monetary history, namely changes in the sterling/dollar exchange rate.

Friedman and Schwartz do of course investigate the linkages between the U.K. and the U.S., and find them to be strong as far as interest rate and price level behaviour are concerned. However, because the correlations between, respectively, the real income series and the money supply series for the two countries are at best weak, they conclude that it is safe to mode1 each economy as if its own money supply was exogenous to its own price and income behaviour. This may well be a safe assumption under a flexible exchange rate regime, and perhaps even under fixed rates when the major factor affecting money growth is domestic credit expansion. However, it is easy to construct models in which it is not safe to do so when the main source of monetary disturbance lies in the behaviour of the foreign price level or in changes in the level of a pegged exchange rate. This is true even if the dynamics of adjustment in such a model rely on a version of the price-specie flow mechanism rather than on the real balance effects that are associated with the "Monetary Approach to Balance of Payments Analysis" as described, say, in Frenkel and Johnson (1976). My scepticism about Friedman and Schwartz's results does not therefore arise as a reaction to the doubts which they express (pp. 28-29; 319) about the importance of the latter analysis. 
The mechanism involved is simple enough. In an economy as open as the U.K., a devaluation, say, not accompanied by an increase in domestic credit expansion may have, by way of the "law of one price", a fairly rapid effect on the domestic prices of tradables. This in turn would tend to create an excess demand for money, whose consequences might be a simultaneous downward pressure on domestic real income and a balance of payments surplus. The net effect would be a period in which real income was relatively low and falling, while prices on average and the money supply were rising. ${ }^{9}$ A few observations like this could easily swamp a weak tendency for money and output to be positively correlated elsewhere in a time series and produce zero correlation results such as Friedman and Schwartz report.

Now the last paragraph presents a possible, but not a definite, explanation of Friedman and Schwartz's U.K. results. However it also presents.a Iine of argument that they would have been forced to address had they carried out for the U.K. the kind of detailed historical analysis that they presented in their (1963) U.S. history, because in such a study, episodes like 1925-, 1931-, 1949-, and 1967- would inevitably have been examined in particular detail. I am not suggesting that Friedman and Schwartz should have carried out such a study of the U.K., of course, but the evidence that they present on money-real-income relationships is one of the places in their work where this reviewer at least feels that the absence of such a prior historical study lessens his confidence in their conclusions.

The doubts I express here spill over to the evidence of the Phillips curve for the U.K. A major discrete change in the exchange rate ought to influence inflation expectations, and Carlson and Parkin (1975) found that the 1967 devaluation did just that in the United Kingdom. It is of some relevance then 
that, ten years ago, I made a preliminary analysis of the timing of the inflation rate relative to the business cycle for the U.K. for the period 1919-1970, excluding 1939-45. I found that, of the cutcele phases I examined, the time path of inflation was qualitatively compatible with a Phillips curve augmented by "error learning" expectations in five of them, and that five of the six false predictions came in the immediate wake of major exchange rate changes. ${ }^{10}$

In short, though Friedman and Schwartz's results are certainly what they say they are, the reader ought not carelessly to interpret them as telling him that there is strong reason to doubt either that a lowering of the monetary growth rate in the U.K. is likely to be followed by a real downturn, or that that downturn is likely to lead to a lower inflation rate. I do not believe that their tests have been finely calibrated enough to come to a definitive conclusion on these matters. 
As the reader will gather, I judge Friedman and Schwartz's results on the effects of monetary growth on prices and real income to be a good deal more tentative than those on the demand for money function. Given that they have so often been accused of understating the importance of interest rates in their monetary analysis, one might have expected their work on this issue also to be tentative. This is not the case. Their chapter on interest rates seems to me to carry with it at least as much authority as that on the demand for money.

It is here that the reader who is looking for an account of Friedman and Schwartz's views on the role played by interest rates in the transmission mechanism of monetary policy should look. The account in question is fuller than those which they have given elsewhere... particularly in dealing explicitly with the role of "liquidity preference" and "loanable funds" effects in that mechanism, but their theory is essentially the same as that which they set out in their (1963b) article on "Money and Business Cycles". Since Monetary Trends does not deal with cyclical phenomena, and since the role of interest rates in the transmission mechanism is primarily a cyclical matter, Friedman and Schwartz do not undertake any systematic empirical investigation of it. Rather, and rightly, they concentrate on the secular influence of money on interest rates as it works through the behaviour of the price level, providing us with what is probably as definitive a study of the "Gibson Paradox"--the positive correlation between the level of nominal interest rates and the level of prices-as we shall ever have. 
To begin with, Friedman and Schwartz cut this famous paradox down to size. They show that it does not occur when there are major structural breaks in the price level series. Prices moved up permanently after both the First and Second World Wars, but interest rates did not. They also show that, though the relationship in question was clearly present in pre-first world war data, and, though less definitely, in interwar year data, it disappeared sometime around 1960 to be replaced by a relationship between the level of nominal interest rates and the rate of change of prices. This latter relationship is of course easily explained in terms of Irving Fisher's (1896) analysis of the effect of anticipated inflation on nominal interest rates. Friedman and Schwartz set themselves two tasks: first, to see whether Fisher's analysis can explain the earlier data as we11; and second, given that it can, to explain why the same mechanism has led to what appears to be qualitatively different behaviour in the recent years. It is well known that Fisher himself explained the Gibson phenomenon by postulating that inflation expectations are formed, with a long average lag, on the basis of previously experienced actual inflation. Thus, by the time actual inflation has influenced expectations, and therefore interest rates, prices are already high. This too is the explanation which Friedman and Schwartz end up with for the earlier periods, albeit with a rather shorter average lag than Fisher.

An explanation such as this needs defending on two fronts. First, the alternative Wicksellian explanation of the phenomenon, later adopted by Keynes, needs to be tested. This analysis locates the source of the Gibson phenomenon in real factors. Increases in the productivity of capital drag prices and the money supply up with them because of the 
discrepancies they cause between the real and money rates of interest. Friedman and Schwartz reject this explanation because the interest rate fluctuations with which they are dealing are mainly confined to nominal rates rather than real rates as we11, and also because relevant money growth rate changes seem to precede the interest rate changes with which they are associated.

Second, backward looking expectations, particularly when they yield what ex post appear to be biased predictions of the actual values of the relevant variable are not popular with advocates of the "Rational Expectations" hypothesis. In defending their position against attacks from this flank, Friedman and Schwartz advance some of their most provocative analysis. They argue that, in forming their expectations, economic agents must often take account of the fact that certain unique events have a positive probability of occurring at ang and that so long as this positive probability persists, it will produce errors in forecasts which are random ex ante but biased ex post. They argue for example that, until the 1896 election settled the issue, there was a positive probability, year after year, that the "free silver" forces would take power in the United States, that their policies would be inflationary, and that this possibility influenced expectations systemmatica1ly before 1896. This argument is certainly convincing in the context in which it is advanced, and does enable Friedman and Schwartz to defend their explanation of the relevant data. However it is also of wider, and potentially devastating importance, not for the notion of rationality itself, but for all work based on that notion which takes it for granted that any expectations formation rule that can be shown ex post to have yielded systematically biased predictions is irrational and 
therefore to be rejected as empirically irrelevant. Friedman and Schwartz do not fail to draw their reader's attention to this broader implication of their analysis.

What about the years after 1960? Here again an important unique event is invoked, namely the apparently permanent shift of the world monetary system from a commodity standard to a dollar standard that was, by then, widely understood to have taken place. Building on the work of Benjamin Klein (1975) Friedman and Schwartz argue that this change fundamentally affected the way in which agents formed their expectations, making them much more aware of price level fluctuations and much less likely to believe that any incipient inflationary tendencies would be reversed, as they would usually have been under a commodity standard. Hence, the recent disappearance of the Gibson phenomenon is put down to the appearance of secular inflation on the scene, and to a public which learns from experience much more rapidly than it did, not because it is better informed, but because it understands that an institutional change has made it rational to pay relatively more attention to the recent past.

If the Chapter on interest rates is one of the longest and most closely argued in the book, that which deals with "Long Swings" in economic growth is one of the shortest and most impressionistic. Given what has gone before, its conclusions are not surprising. The Swings in question seem mainly to be confined to the United States, and are interpreted as being the result of episodic shocks reverberating over long periods, rather than of inherent cyclical tendencies in the economy. The episodic shocks in question are said to have been mainly monetary in nature. This brief chapter will certainly convince the reader that monetary 
factors are potentially important in Long Swings, and need further investigation. Whether it will also convince him that those monetary factors are their prime cause is a different matter, and it would take a reviewer better versed than this one in the relevant literature to hazard even an informed guess aboüt the likelihood of Friedman and Schwartz being right about this question. It is certainly worth investigating though, and one can only hope that someone at the National Bureau will do so with the care that it deserves.

VI.

As I said at the beginning of this essay, Monetary Trends is an attempt to settle the debate between the "Keynesian Economics" and the "Quantity Theory of Money" in the light of empirical evidence. Any review of it must face the question of the extent to which the 'Quantity Theory" is validated by Friedman and Schwartz's work. In some respects it emerges as a clear winner. The demand for money is a stable function of a few arguments, and that brand of Keynesianism which denied this (and it did exist and was influential) is surely wrong. Moreover, changes in the quantity of money do exert a systematic influence on money income, particularly on prices, and that effect is transmitted to nominal interest rates. These aspects of Friedman and Schwartz's "Quantity Theory" are well supported by the data, and the alternative Wicksell-Keynes mechanism, which relies on fluctuations in the productivity of capital to explain the same set of inter-relationships does not fare so well. Friedman and Schwartz's conjecture that long swings in real growth may be largely a monetary phenomenon is not really part of their version of the "quantity theory", but it is a provocative idea worth 
further investigation, and if further work proves it true, it will provide even more content to the slogan "Money Matters". aimost

But $_{f}$ all this support for a monetary interpretation of macroeconomic behaviour comes from data for cycle phase averages. A Keynesian can find a crumb of comfort in the fact that, even here, when United States data for the 1930s are in the sample, a few of the hypotheses attributed to him find support. ${ }^{11}$ Here lies the key question left inter-wer yeirs open by this book: were the 1930s an anomaiy? Friedman and Schwartz suggest that they were, but they do not seriously consider the alternative explanation, to which I have referred earlier, of this period as an "outlier": namely that the 1930s is probably the one peciod where the use of cycle phase averages as the basic unit of observation does not purge the data of cyclical influences. If that is true, then the mter-uw yens I930s may be an anomoly only in the sense that forces which are present in all cycles are more readily observable there, and have intruded into Friedman and Schwartz's data.

In that event, the contribution of Monetary Trends will prove to have been to develop systematic empirical support for a version of the "Quantity Theory" which describes the secular nature of the interrelationships of money, income, prices and interest rates, and which therefore characterises the steady state properties which ought to be inherent in any satisfactory theory of the cycle. Such a theory could not be fully "Keynesian" in the sense in which Friedman and Schwartz use the term. However, Keynesian-style liquidity preference effects could play a role in the transmission mechanism for monetary policy within the cycle, as they themselves explicitly point out. Also, an expectations augmented Phillips curve could play an important role within the cycle, 


\section{argued eariós.}

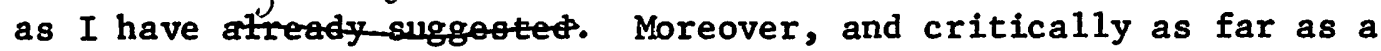
Keynesian would be concerned, a version of the Quantity Theory such as Friedman and Schwartz set out, in which a downturn in money income is attributable to the existence of an excess demand for money, could easily enough accommodate that offsetting excess supply of labour to which a Keynesian would usually refer as involuntary unemployment. The foregoing paragraph is, of course, speculative, and the fact that Friedman and Schwartz themselves refer with approval to the Fisherlan "aggregate supply curve" interpretation of the Phillips curve (p. 441) suggests that they might not approve of the direction it takes. Even so, after the publication of Monetary Trends, it is clearer than ever that it is the cycle that demands the attention of macroeconomists. In establishing the nature of the secular relationships which provide a background to the cycle, Friedman and Schwartz have made an important indirect contribution to its study; and this is to say nothing of its- Teir direct contributions, which, as the reader of this review will have gathered are of the highest importance in their own right. Monetary Trends is then, as I remarked at the outset, a marvellous book. 


\section{Footnotes}

*A Review of Milton Friedman and Anna J. Schwartz, Monetary Trends in the United States and the United Kingdom: Their Relation to Income, Prices, and Interest Rates, 1867-1975; Chicago, University of Chicago Press for the National Bureau of Economic Research, 1982, pp. $664+x x x i$, $\$ 48.00$.

Before preparing this essay, I was fortunate enough to have access to other review essays on this book by Charles Goodhart, Robert Hall, and Thomas Mayer, which will appear in the Journal of Economic Literature. It would be surprising if those reviews did not influence me to some degree, and I am grateful to their authors for whatever lines of thought they may have stimulated. I am also grateful to Moses Abramowitz for use ful correspondence about certain issues dealt with in this book. His ideas too have undoubtedly crept into this essay.

$1_{\text {Friedman and Schwartz (1963b) thus remains the authors' most }}$ detalled empirical account of the role of money in the cycle.

2 The reader is also reminded that this book is the fourth of a series whose preparation got under way in the late 1950 s and whose first volume appeared in 1963.

${ }^{3}$ of course instability in a short-run demand for money function presents much more of a problem to a Keynesian such as Modigliani (e.g., 1977), who wishes to use money for stabilisation purposes, than it does to a quantity theorist who advocates a monetary rule of some sort.

${ }^{4}$ Nor does this Quantity Theory induced relationship between the rate of change of real income and that of prices preclude the operation of a Phillips curve. The model set out in Laidler (1975) Chapter 7, consists 
of nothing but these two relationships and proved to have considerable empirical content when confronted with post Korean War U.S. annual data.

${ }^{5}$ Strictly speaking, this lagged price change variable is a proxy for the combined effects of anticipated inflation and anticipated money growth. The reader of Monetary Trends will notice that Friedman and Schwartz use different inflation expectations proxies when dealing with the demand for money, the Phillips curve and interest rates. There is nothing wrong with this, since expectations over different time horizons are relevant to different decisions, as they often remark themselves. Nevertheless a little more guidance than they give us about the relationships among these different proxies, some discussion of the term structure of inflation expectations, would have been welcome.

${ }^{6}$ The reader is reminded that the notion of a permanent inflationunemployment trade-off was conventional wisdom in the 1960 s, when this book was started. He should also note that Friedman and Schwartz are much more careful about stating the limitations of their findings on the Phillips curve in the chapter dealing with it, than they are in their final summary chapter. Compare pp. 462-64 with p. 622 .

${ }^{7}$ And none of this is to mention the fact that Phillips himself originally developed his curve to 1 ink prices and output in a model of the cycle. See Phillips (1954).

${ }^{8}$ It is, however, worth pointing out that Jonson (1976), who uses U.K. annual data for almost the same period as Friedman and Schwartz to construct a sma11 model of that economy, finds the links between money and real income to be very weak. 
${ }^{9}$ A simple prototype model with the properties I am discussing here was developed by this author in 1972, and is described in Laidler (1975) Chapter 9.

${ }^{10}$ See Laidler (1975) Chapter 10. As the reader will see below, Friedman and Schwartz are extremely sensitive to the role of unique events in influencing behaviour when they discuss the influence of money on interest rates. The event they single out there is the 1896 election which marked the final defeat of the Silver party in the United States. 11 The reader will recall that the Friedman and Meiselman (1963) study which pitted velocity against the multiplier, found that only in the 1930s was there any support to be found for the latter concept. 


\section{Bibliography}

Bronfenbrenner, M. and Holtzman, F. D. (1965), "A Survey of Inflation Theory," in AEA and RES, Surveys of Inflation Theory, Vol. I, London and New York, Macmillan and St. Martins Press.

Cagan, P. (1965), Determinants and Effects of Changes in the Stock of Money, New York, Columbia University Press for the N.B.E.R.

Cagan, P. (1969), "Theories of Mild Continuing Inflation: A Critique and Extension," in S. Rousseas (ed.), Inflation: Its Causes, Consequences and Control, Wilton Conn., The Calvin K. Kazanjian Economics Foundation, Inc.

Car1son, J. A. and Parkin, J. M. (1975), "Inflation Expectations," Economica, NS 42 (Feb.), 183-99.

Committee on the Working of the Monetary System (The Radcliffe Committee) (1959), Principal Memoranda of Evidence and Minutes of Evidence, London, HMSO.

Fisher, I. (1896), Appreciation and Interest, Cambridge, Mass., AEA. Frenke1, J. A. and Johnson, H. G. (eds.) (1976), The Monetary Approach to the Balance of Payments, London, George A1len and Unwin. Friedman, M. (1982), "Defining 'Monetarism'", Newsweek, Ju1y 12, 64. Friedman, M. and Meiselman, D. (1963), "The Relative Stability of Monetary Velocity and the Investment Multiplier in the United States 1898-1958," in Commission on Money and Credit Stabilization Policies, Englewood Cliffs, New Jersey, Prentice-Hall.

Friedman, M. and Schwartz, A. J. (1963a), A Monetary History of the United States 1867-1960, Princeton, N.J., Princeton University Press for the NBER. 
Friedman, M. and Schwartz, A. J. (1963b), "Money and Business Cycles," Review of Economics and Statistics, 43, February, Part 2, 32-64.

Friedman, M. and Schwartz, A. J. (1970), Monetary Statistics of the United States, New York, Columbia University Press for the NBER. Gordon, R. J. (ed.) (197\%), Milton Friedman's Monetary Framework, Chicago, University of Chicago Press.

Jonson, P. D. (1976), 'Money and Economic Activity in the Open Economy: The United Kingdom 1880-1970," Journal of Political Economy 84 (Sept./Oct.), 979-1012.

Jonson, P. D., Moses, E. and Wymer, C. (1976), A Minimal Model of the Australian Economy, Sydney, Reserve Bank of Australia, mimeo. Klein, B. (1975), "Our New Monetary Standard: The Measurement and Effects of Price Uncertainty," Economic Inquiry 13 (Apri1), 461-84. Laidler, D. (1975), Essays on Money and Inflation, Manchester, University of Manchester Press, Lipsey, R. J. (1981), "Presidential Address: The Understanding and Control of Inflation: Is there a Crisis in Macroeconomics," Canadian Journal of Economics 14 (November), 545-576.

Modigliani, F. (1977), "The Monetarist Controversy or, Should we Forsake Stabilization Policies," American Economic Review 67 (March), 1-19. Phillips, A. W. (1954), "Stabilization in a Closed Economy," Economic Journal 44 (June), 290-323.

Phillips, A. W. (1958), "The Relation Between Unemployment and the Rate of Change of Money Wage Rates in the United Kingdom," Economica, NS 25 (November), 283-99.

Samuelson, P. A. and Solow, R. M. (1960), "Analytical Aspects of AntiInflation Policy," American Economic Review 50 (March), 177-94. 